\title{
Angloamericano y galicismos en el español actual: una cuestión de huellas y préstamos
}

\section{Stéphane Oury}

\section{(2) OpenEdition}

1 Journals

Edición electrónica

URL: https://journals.openedition.org/cher/3347

DOI: $10.4000 /$ cher.3347

ISSN: 2803-5992

Editor

Presses universitaires de Strasbourg

\section{Edición impresa}

Fecha de publicación: 27 junio 2017

Paginación: 171-182

ISBN: 978-2-86820-961-0

ISSN: $1968-035 X$

\section{Referencia electrónica}

Stéphane Oury, «Angloamericano y galicismos en el español actual: una cuestión de huellas y préstamos», reCHERches [En línea], 18 | 2017, Publicado el 01 diciembre 2021, consultado el 14 diciembre 2021. URL: http://journals.openedition.org/cher/3347 ; DOI: https://doi.org/10.4000/cher 3347

\section{cc) (i) (2)}

Ce(tte) œuvre est mise à disposition selon les termes de la Licence Creative Commons Attribution Pas d'Utilisation Commerciale - Partage dans les Mêmes Conditions 4.0 International. 


\title{
Angloamericano y galicismos en el español actual: una cuestión de huellas y préstamos
}

\author{
StÉPHANE OURY*
}

$\mathrm{T}$ rataremos aquí de desenmarañar las influencias entre el elemento francés e inglés y de discernir las huellas recíprocas que dejaron el uno en el otro así como sus repercusiones en algunos préstamos de la lengua española.

Nos interesaremos primero por la huella fonológica del francés que modifica el esquema acentual esperado en el préstamo del inglés. Nos centraremos luego en el impacto de frecuencia del inglés en los galicismos del español, beneficiándose quizá estos del inesperado apoyo del angloamericano que contribuye a su difusión en castellano. Señalaremos, por fin, que no siempre es tan fácil identificar el origen del préstamo, debido a unas huellas tramposas, pudiendo el anglicismo sincrónico ocultar un galicismo en diacronía.

\section{La huella prosódica del galicismo en algunos anglicismos}

Si el francés afecta a veces el significante visible del anglicismo, o sea su imagen gráfica: pensemos en palabras como confort ( $\mathrm{y}$ no «comfort»), rallye ( $\mathrm{y}$ no «rally»)... más a menudo deja una huella en el esquema acentual agudo de la palabra.

Valentín García Yebra le dedicó un libro al fenómeno en 1999 en el que apunta nada menos que 223 palabras del castellano, de origen extranjero ${ }^{1}$, que llevan la marca prosódica del francés que delata un tránsito por la lengua de Molière. Entre estas palabras, podemos señalar algunos anglicismos que, en vez de ser paroxítonos (o a veces proparoxítonos) como era de esperar, son oxítonos, impactados por el francés, que resultó ser su canal de entrada.

* Profesor titular de la Universidad de Lorraine-Centre de recherches Écritures, équipe 3943.

1 Del australiano (bumerán), del hindi (bungaló), del tamil (catamarán), del hebreo (edén), del griego (electrón), del checo (robot)... 
De hecho, lleva el anglicismo en estos casos, en su significante o sea en su imagen acústica la huella, la traza del francés: el acento tónico que recae en la última sílaba, tan característico de los galicismos, como se puede observar en la siguiente lista:

Boicot: del nombre del primer administrador irlandés Boycott a quien se le aplicó el boicoteo en 1880. Es palabra paroxítona en inglés. Pasa al castellano por el francés «boycott» que le dejó su marca prosodica oxítona. No figura en el DRAE hasta 1970.

Charlestón: palabra incluida por el DRAE en 1992, del nombre de la ciudad norteamericana de Carolina del Sur Charleston. Pero la palabra angloamericana es esdrújula. La presencia en francés está documentada ya en 1925 .

Galón: $\quad$ la palabra inglesa gallon (llana) es adoptada por el francés en 1669.

Interviú: integrada por el DRAE en 1992, la palabra está documentada en francés desde 1884. Interview pasa de proparoxítona a oxítona en francés.

Jersey: la palabra inglesa llana es integrada en 1667 en francés, pero solo aparece en el DRAE en 1970, después de pasar por el filtro francés.

Macadam: del antropónimo Mc Adam. Compite a veces en español con la versión españolizada macadán, también aguda y desplazó el acento tónico de la penúltima a la última sílaba.

Mormón: del nombre de un profeta inventado, Mormon, voz llana, presente en francés desde 1850, pero tranformada en voz aguda.

Tartán: afirma con razón en su edición de 1992 (no lo hacía en las de 1970 y 1984) el tránsito por el francés, pero un origen inglés.

Vagón: aparece «wagon» (aguda) en francés en 1780 (DHLF) procedente del inglés wagon (llana). Aparece en castellano en 1884. Tanto el acento tónico como el acento gráfico son de origen francés.

Dejaremos aquí esta lista para nada exhaustiva y señalaremos para terminar dos casos particulares y singulares: el de una huella española en el lexema pero francesa en la prosodia en un seudoanglicismo y el de la marca fonológica del inglés en un galicismo:

- Aligator, palabra oxítona del castellano fue fomada del francés «alligator», también oxítona que la tomó en su tiempo del inglés alligator (paroxítona). Ahora bien, esta se había tomado del... español «el lagarto», por aglutinación y deformación (notemos que la forma intermedia «aligarto» está documentada).

- Chófer: es el caso contrario a los precedentes, dejando aquí el inglés su huella acentual paroxítona en un galicismo que es oxítono en francés, habrá pasado al castellano por el inglés (/'’əufə/ en inglés > /'tfofer/ en castellano). Notemos que el canal de entrada debió en cambio de ser el francés en español de América (a través o no de la variante norteamericana oxítona) que mantuvo el acento tónico del francés: chofer $<$ chauffeur.

Como acabamos de ver, las huellas pueden ser múltiples y resultan a veces difíciles de identificar y aislar. Pero ¿qué sería de una huella que afectara la frecuencia de uso? 


\section{El aporte angloamericano como factor de revitalización del galicismo léxico}

$\mathrm{Al}$ escuchar algunos galicismos como «debut» (artístico o deportivo), «affair» (escándalo), «déjà-vu» (impresión de experiencia ya vivida) o «amateur» (no profesional), tanto en inglés como en castellano, nos planteamos cuál podía ser el volumen de galicismos común al angloamericano y al castellano y en qué medida esa presencia en inglés podía ayudar a su difusión en español.

Decidimos hablar de angloamericano más que de inglés por el impacto que tiene esta lengua, beneficiándose de un prestigio y una difusión que no dejan de recordar los que conociera el francés en el siglo Xviır. Llegó a hablar de "Phare Ouest» Claude Hagège (1987: 79) al respecto: «L'omniprésence de l'anglais américain n'est pas difficile à expliquer. La civilisation américaine a acquis ou consolidé dans de nombreux domaines, depuis quarante ans, une priorité chronologique ou une supériorité qui font de ces domaines des fiefs des ÉtatsUnis ${ }^{2}$.» La rapidez y la eficacia de su difusión por los medios informativos del siglo Xxi la hace más presente aún y en casi todas las lenguas.

Pero puede sin embargo que dicho angloamericano se vuelva un aliado del francés que permita revitalizar los galicismos del castellano que los toma a veces por anglicismos.

Nuestra metodología será ésta: una lectura sistemática de la última edición del Oxford Dictionary of English ${ }^{3}$ nos revelará los galicismos allí presentes. Cruzaremos esta lista con las establecidas en trabajos anteriores, à partir de la lexicografía española actual: DRAE en Oury 2003, DEA (Diccionario del español actual), DCL (Diccionario Clave), DUE (Diccionario de Uso del Español), DS (Diccionario Salamanca) en Oury 2011. Cuestionaremos por fin la frecuencia de dichos préstamos en sincronía y en diacronía para establecer si su frecuencia es alta y si progresa.

Los resultados parciales confirman la hipótesis inicial: un número conspicuo de galicismos compartidos por el inglés y el castellano salta a la vista: 158 voces aparecen en el Oxford Dictionary of English y por lo menos uno de los diccionarios del español actual (ver anexo 1).

Se confirman los campos de la gastronomía («restaurant, menú, gourmet, maître d'hôtel, mousse, foie gras, soufflé, croissant, consomé, crepe, baguette, chef...»), de la moda («bustier, brassier, deshabillé, eau de toilette, boutique, prêt-à-porter, mode, élite, chic...») ya señalados en otros estudios. Estos galicismos parecen reforzados por el angloamericano: 15 de ellos forman parte

2 Traducción mía: «La omnipresencia del inglés americano no es difícil de explicar. La civilización americana adquirió o consolidó en muchos sectores, desde hace cuarenta años, una prioridad cronológica o una superoridad que convierten dichos sectores en coto vedado de Estados Unidos.»

3 Oxford Dictionary of English, 2010, Oxford, Oxford University Press. 
de los 100 galicismos más frecuentes del español ${ }^{4}$ o sea del $0,05 \%$ de los más frecuentes como «hotel, bloque, restaurant, rol, dame, menú, courage, élite, ballet, chófer, debut, calibre, chalet, cheque, pelotón». Muchos de ellos tienen una frecuencia alta («souvenir, paté, morgue, masacre, debacle, maillot, etiqueta, croquis, cabaret, cachet, beige, bulevar, bagaje...») y que parece ir creciendo (fuente inventario CREA 2003/2013).

El promedio de la evolución es del $110 \%$ bruto corregido (quitando los dos extremos) en el 94\% (ver anexo 1). Las voces de progression más alta son «argot, art deco, avant-garde, bibelot, brioche, cachet, crêpe, croissant, debut, deshabillé, élite, escalope, fondue, grand prix, ménage à trois, milieu, première, rendez-vous, ragoût, soufflé, tête à tête», con un aumento de un $100 \%$ o más, sobresaliendo agunas voces como «debut, élite» $(+2000 \%)$. Notemos que algunas voces acumulan los dos factores (progesión y frecuencia): podemos volver a citar «debut, élite» con respectivamente 1341 y 1652 ocurrencias. Notemos por otra parte que hay una progresión de conjunto: de hecho solo el 0,6\% bajó su frecuencia de uso cuando el $3,8 \%$ se mantuvo igual y la enorme mayoría, el, 95,6\% progresó.

Para relativizar estos resultados brutos, decidimos cuestionar el impacto absoluto y el impacto relativo: ¿en qué medida no progresaron todos los galicismos en español en diez años (estén compartidos o no con el inglés)?

Recurrimos para ello a una muestra testigo de los cien primeros galicismos del DRAE (ver anexo 2) de frecuencia superior a cero. Llegamos, aplicándole el factor de corrección, a un $86 \%$ de progresión. El 12\% de las voces bajó su frecuencia de uso, el $17 \%$ se mantuvo igual y el $71 \%$ progresó.

Podemos concluir que sí hubo impacto del angloamericano pero relativo (un $8 \%$ más que la muestra testigo). Dicho impacto parece impedir el declive de frecuencia y se beneficia a algunas voces que llegan a formar parte de los galicismos más frecuentes del español («hotel, restaurant, rol, menú, ballet»). Algunos tienen una frecuencia muy alta («argot, art deco, dossier, rendez-vous, croissant, menage à trois, tête-à-tête...») y algunos, por fin, sin duda los más impactados, suman a esa frecuencia alta una progresión muy alta («élite, debut»).

El galicismo se beneficia innegablemente de la marca prestigiosa del angloamericano que deja en él una huella de frecuencia. El inglés viene a ser un canal de difusión de los galicismos en castellano pero también en otros idiomas, convirtiéndose el galicismo a veces en internacionalismo. No estaría de más investigar la presencia de dichos galicismos en otras lenguas: recordemos que "champagne, menu, croissant, champignon» penetraron en italiano, en alemán y en inglés; «bonbon, mayonnaise, bechamel» también pasaron al árabe. Hasta encontramos «assiett» ('plato') en sueco y noruego. «Corset, deshabillé, chic» están presentes en muchas lenguas; «rouge» ('pintalabios') se documenta en árabe, persa, griego, húngaro o turco y con el sentido de 'colorete', en

4 De los 1758 galicismos documentados in Oury 2003. 
inglés y alemán. Solo son una muestra de ejemplos significativos de galicimos internacionales que salen en Treps (2009), pero un estudio global queda por realizar.

\section{¿Anglicismo o galicismo?: del seudoanglicismo al préstamo de ida y vuelta}

Parece haber en inglés más galicismo escondido de lo que parece. Entraron en una época remota y se adaptaron tan bien que cuesta identificarlos. To catch o to chase, por ejemplo, proceden de dos formas dialectales de «chaser», actual «chasser», car de una forma normanda de «char» (forma presente para coche en francés de Quebec), to travel proviene de «travailler» (en su sentido etimológico de sufrimiento, de algo que cuesta trabajo), trip de «treper» (moverse, en francés antiguo). A veces se mantuvo la forma tal cual: tour.

Lo que tomamos por anglicismo en sincronía resulta ser a veces un galicismo en diacronía. Algunos préstamos del francés, remotos e integrados por el inglés volvieron al francés ${ }^{5}$ o entraron en castellano como «anglicismos» cuando solo son galicismos de ida y vuelta.

Los anglicismos para «vaqueros» en francés: «(blue) jean» o «denim» proceden en realidad del francés (por elipsis) «bleu de Gênes» y (por elipsis y aglutinación) de «de Nîmes». "Grog» ${ }^{6}$ (bebida caliente con ron agua y limón) pasó al francés del antropónimo Old Grog, apodo del almirante inglés Vernon que solía mezclar la ración de sus soldados con agua. Ahora bien, debía ese mote al hecho de llevar un abrigo de tela grogram, adaptación... del francés "gros grain». Dejó en cambio el inglés una palabra derivada: "groggy» (aturdido, atontado) en francés y "grogui» en castellano.

Podemos leer al respecto en Walter (1999: 181-183): «Ces quelques rappels ne font que confirmer le retour au pays natal de quantité de mots français, parfois sous une nouvelle forme, souvent avec un sens nouveau. [...] Après plusieurs siècles d'adaptation à l'anglais, ces vieux mots français se sont fait une nouvelle jeunesse» ${ }^{7}$.

No faltan los ejemplos que están documentados en francés y en español. Vienen a continuación algunos casos:

Tenis: procede del inglés tennis con simplificación de las geminadas y la marca acentual paroxítona del inglés. Este la tomó del francés «tenetz» $(\mathrm{xv})$, antiguo imperativo de «tenir» en segunda persona del plural (hoy «tenez»), que se solía pronunciar al sacar en el juego de palma.

5 Se critican en francés algunos anglicismos que en realidad no lo son: challenge $<\mathrm{f}$. ant. chalonge, rosbeef < rôt de bif (bœuf), budget < bougette, flirter $<$ fleureter...

6 Está la palabra en el DRAE 22 con la etimología reductora «del inglés».

7 Traducción mía: «Estos pocos recuerdos no hacen más que confirmar el retorno a su tierra natal de cantidad de voces francesas, a veces bajo una forma nueva, a menudo con un significado nuevo. [...] Después de siglos de adaptación al inglés, esas antiguas palabras francesas se han hecho un estiramiento de piel.» 
Sport: del inglés sport, de la forma antigua disport (xiv) que se tomó del francés antiguo «desport» variante de «deport» (entretenimiento), que también dio el español «deporte».

Récord: del inglés record (xIv) que tomó del francés antiguo «record/recort» (recuerdo).

Estrés: del inglés stress (xIV), de la forma antigua distress que se tomó del francés antiguo «destresse» (causa de angustia, de miedo, hoy «détresse»).

Test: del inglés test (xIx), 'prueba', que procede del inglés test (xvI), que fue tomada del francés antiguo «test», variante de «têt» (vasija de barro para probar la existencia de oro en el lecho de un río o para aislar metales preciosos).

Podríamos añadir a estos ejemplos, señalados por Gómez Capuz (2004: 61) y Walter (1999: 182) algunos más, siguiendo en eso al TLF (Trésor de la langue française) y al FEW (Französisches Etymologisches Wörterbuch), como:

Bar: del angloamericano bar, elipsis de bar-room (xviII), del inglés bar (xv), en el sentido de despacho de bebidas, de barre (XIII), en el sentido de fortificación que se tomó del francés antiguo «barre» (con en sentido de «barrera»).

Fashion: del inglés fashion (xIx), a la moda, del inglés fashion (xIV), que se tomó del francés «façon».

Gay: del inglés gay (1960), en el sentido de 'homosexual', del inglés medio gay, que se tomó del francés antiguo «gai».

Pedigrí: del inglés pedigree (xv), que se tomó del francés medio «pié (pied) de grue» (marca de tres trazos usada en genealogía).

Penalty: del inglés penalty (1885), en el sentido del deporte, del inglés penalty (xvI), que se tomó del francés "pénalité».

Scout: del inglés scout (xx), boy scout, del inglés scout (xvI), que se tomó del francés antiguo «escoute» ('espía').

Suspense: del inglés suspense (xv), que se tomó del francés antiguo «suspens» (angustia, aprensión).

Ticket: del inglés ticket ( $\mathrm{xvI}$ ), que se tomó del francés «étiquette», forma heredada del francés medio «estiquet», por extensión metonímica (de lo que contiene el soporte [cf. etiqueta] al soporte mismo).

O sea que hay que ir con pies de plomo a la hora de zanjar si tal extranjerismo es anglicismo porque a veces, «aunque el galicismo se vista de anglicismo, galicismo se queda». Pero el caso es que, centrándonos en la huella superficial, más aparente, nos olvidamos a veces de la huella profunda, más invisible.

Otro caso es el seudoanglicismo (palabra que parece ser inglesa pero que no se usa así en inglés) o sea un neologismo francés «a la manera de» un anglicismo.

Puede ser una creación propia:

Footing: creado, a imitación de jogging sobre la base «foot». No deja de recordar ese neologismo «a la manera de» a otros del español actual como «puenting» o la compañía aérea «Vueling».

Auto-stop: creado a partir de un elemento griego y de un elemento inglés.

También puede aparecer por cambio semántico: 
Smoking > esmoquin: «action or habit of inhaling and exhaling the smoke of tobacco or a drug», en inglés, que pasó a «traje de etiqueta» en francés y en castellano, equivalente del inglés dinner jacket.

Book: pasó de «libro» a portfolio, en el ámbito de la moda.

Viene a ser a veces el resultado de una elipsis:

Parking: $\quad$ elipsis de parking lot.

Camping: elipsis de camping ground o camping site.

Así que se confirma que todas estas voces son extrajerismos, pero se han tomado en español del... francés. Algunos de estos ejemplos se han sacado de Isabel Balteiro y Miguel Ángel Campos (2012: 233-260). Aparecen otros más en Lorenzo (1992: 6-7). Los define este de la manera siguiente: «[los anglicismos] son [...] galicismos anglificados y algunos otros, en minoría, creaciones del francés con ropaje inglés». Añade las voces pressing, speaker como galicismos semánticos y anglicismos léxicos.

De modo que, cuidado, no siempre es anglicismo el que lo parece: las apariencias engañan.

\section{Conclusión}

Las huellas, en los préstamos, no son siempre tan nítidas como podemos pensar. Son a la vez singulares y plurales e impactan varios niveles del significante y del significado. Hay que ir con pies de plomo y mirarlos con lupa.

Como era de esperar, las influencias no son unidireccionales. Si interfiere hoy mucho el inglés en el francés, sigue este, después de haberlo impactado mucho a lo largo de la historia, insinuándose en su pronunciación y en algunos campos de su léxico.

Y si, con la globalización, el angloamericano resulta ser un aliado del francés al difundir y/o popularizar tantos galicismos del pasado y algunos del presente, el español también, por su difusión creciente en Estados Unidos permitirá imponer algunos de los no pocos galicismos que contiene.

\section{Bibliografía}

Balteiro I., Campos M.A, 2012, «False anglicisms in the Spanish language of fashion and beauty», Ibérica 24, p. 233-260, http://www.aelfe.org/ documents/16_24_Balteiro.pdf [Consulta: 16/06/2016].

García Yebra V., 1999, Diccionario de galicismos prosódicos y morfológicos, Madrid, Gredos.

Gómez Capuz J., 2004, La inmigración léxica, Madrid, Arco Libros.

Hagège C., 1987, Le français et les siècles, Paris, Odile Jacob.

Lorenzo E., 1992, «La lengua española, hoy (VI); anglicismos» in: Ensayos, Madrid, Fundación March, p. 3-14, http://digital.march.es/ensayos/fedora/ repository/ensayos:223/OBJ [Consulta: 16/06/2016]. 
Oury S., 2003, L'Emprunt lexical de l'espagnol au français dans la $22^{e}$ édition du Diccionario de la Real Academia de la lengua Española, Thèse de Doctorat, Nancy.

Oury S., 2011, «Le gallicisme lexical récent dans les dictionnaires espagnols actuels: l'usage lexicographique et l'usage en lexicographie», in: Lexicographie et métalexicographie en langue espagnole, Valenciennes, Presses universitaires de Valenciennes, p. 241-277.

Treps M., 2009, Les mots migrateurs. Les tribulations du français en Europe, Paris, Seuil.

Walter H., 1999, L'aventure des mots français venus d'ailleurs, Paris, Laffont.

\section{Anexos}

\section{Galicismos compartidos}

Número de ocurrencias y evolución de la frecuencia (DI: dato indisponible)

\begin{tabular}{|c|c|c|c|c|}
\hline lexema o lexía (alomorfo) & CREA 2003 & $\begin{array}{c}\text { frecuencia: } \\
\text { ocurrencias } \\
\text { en CREA } 15 / 10 / 2013\end{array}$ & $\begin{array}{c}\text { total ocurrencias } \\
\text { CREA } 2013\end{array}$ & Evolución \\
\hline affair (afer) & 200 & $243+11$ & 254 & $+25 \%$ \\
\hline à gogo & $\mathrm{DI}$ & 1 & 1 & $\mathrm{DI}$ \\
\hline à la carte & $\mathrm{DI}$ & 0 & 0 & $\mathrm{DI}$ \\
\hline à la mode & $\mathrm{DI}$ & 3 & 3 & $\mathrm{DI}$ \\
\hline amateur & 253 & 374 & 374 & $+50 \%$ \\
\hline amour & $\mathrm{DI}$ & 110 & 110 & $\mathrm{DI}$ \\
\hline amour-propre & $\mathrm{DI}$ & 0 & 0 & $\mathrm{DI}$ \\
\hline ampere & 1 & 1 & 1 & $=$ \\
\hline applique (aplique) & 564 & 564 & 694 & $+20 \%$ \\
\hline argot & 62 & 225 & 225 & $+300 \%$ \\
\hline arriviste (arribista) & 9 & 9 & 9 & $=$ \\
\hline art deco & 7 & 56 & 56 & $+800 \%$ \\
\hline art nouveau & 35 & 43 & 43 & $+20 \%$ \\
\hline attaché & 7 & 8 & 8 & $+10 \%$ \\
\hline avant-garde & 4 & 10 & 10 & $+150 \%$ \\
\hline baccarat (bacarrá) & 19 & $10+19$ & 29 & $+50 \%$ \\
\hline bagage (bagaje) & 386 & $3+498$ & 501 & $+40 \%$ \\
\hline baguette & 11 & 14 & 14 & $+25 \%$ \\
\hline ballet & 1163 & 1381 & 1381 & $+20 \%$ \\
\hline begonia & 11 & 13 & 13 & $+20 \%$ \\
\hline beige & 151 & 203 & 203 & $+35 \%$ \\
\hline berline (berlina) & $\mathrm{DI}$ & $0+151$ & 151 & $\mathrm{DI}$ \\
\hline bibelot & 7 & 6 & 20 & $+200 \%$ \\
\hline bidet (bidé) & 44 & $53+56$ & 109 & $+120 \%$ \\
\hline billet-doux & $\mathrm{DI}$ & $5+5$ & 10 & $\mathrm{DI}$ \\
\hline billion (billón) & 471 & $0+558$ & 558 & $+20 \%$ \\
\hline bloc (block, bloque) & $\mathrm{DI}$ & $138+56+4956$ & 5150 & $\mathrm{DI}$ \\
\hline blonde & $\mathrm{DI}$ & 7 & 7 & DI \\
\hline blouse (blusa) & 817 & $0+990$ & 990 & $+20 \%$ \\
\hline bon vivant & 16 & 20 & 20 & $+25 \%$ \\
\hline boulevard (bulevar) & 210 & $67+264$ & 331 & $+50 \%$ \\
\hline bouquet & 48 & 67 & 67 & $+40 \%$ \\
\hline boutade & 42 & 58 & 58 & $+40 \%$ \\
\hline boutique & 171 & 201 & 201 & $+20 \%$ \\
\hline brasserie & 5 & 5 & 5 & $=$ \\
\hline
\end{tabular}




\begin{tabular}{|c|c|c|c|c|}
\hline brassière (brassier, brassiere) & 21 & $5+10+12$ & 27 & $+30 \%$ \\
\hline brioche & 2 & 5 & 5 & $+150 \%$ \\
\hline brut & DI & 29 & 29 & $\mathrm{Dl}$ \\
\hline buffet & 107 & 147 & 147 & $+40 \%$ \\
\hline bureau & 32 & 33 & 33 & $+5 \%$ \\
\hline bustier & 2 & 2 & 2 & $=$ \\
\hline cabaret (cabaré) & $\mathrm{DI}$ & $488+34$ & 522 & $\mathrm{DI}$ \\
\hline cabriolet (cabriolé) & 16 & $10+16$ & 26 & $+50 \%$ \\
\hline cache & DI & 27 & 27 & DI \\
\hline cachet (caché) & 112 & $32+195$ & 227 & $+100 \%$ \\
\hline calibre & 1000 & 1324 & 1324 & $+30 \%$ \\
\hline camouflage (camuflaje) & 127 & $2+180$ & 182 & $+40 \%$ \\
\hline cancan (cancán) & 28 & $2+31$ & 33 & $+20 \%$ \\
\hline canaille & $\mathrm{DI}$ & 6 & 6 & $\mathrm{DI}$ \\
\hline canapé & 88 & 99 & 99 & $+10 \%$ \\
\hline carousel (carrusel) & 89 & $0+115$ & 115 & $+25 \%$ \\
\hline chaise longue & 54 & 61 & 61 & $+10 \%$ \\
\hline chalet (chalé) & 1102 & $779+483$ & 1262 & $+10 \%$ \\
\hline chapeau (chapó) & 15 & $16+3$ & 19 & $+20 \%$ \\
\hline charcuterie (charcutería) & 27 & $0+40$ & 40 & $+40 \%$ \\
\hline chassis (chasis) & 125 & $7+182$ & 189 & $+50 \%$ \\
\hline chauffeur (chófer, chofer) & 1827 & $36+945+1270$ & 2351 & $+25 \%$ \\
\hline chef & DI & 215 & 215 & $\mathrm{DI}$ \\
\hline cheque & $\mathrm{DI}$ & 1202 & 1202 & $\mathrm{DI}$ \\
\hline chic & 143 & 173 & 173 & $+25 \%$ \\
\hline claque (clac) & 60 & $32+51$ & 83 & $+40 \%$ \\
\hline cliché & 126 & 152 & 152 & $+25 \%$ \\
\hline collage & 221 & 313 & 313 & $+40 \%$ \\
\hline consommé (consomé) & 76 & $1+129$ & 130 & $+80 \%$ \\
\hline couplet (cuplé) & 56 & $5+66$ & 71 & $+30 \%$ \\
\hline courage (coraje) & 1456 & $5+1816$ & 1821 & $+20 \%$ \\
\hline crème de la crème & 21 & 11 & 11 & $-50 \%$ \\
\hline crêpe (crepe) & 10 & $8+14$ & 22 & $+120 \%$ \\
\hline croissant (cruasán) & 4 & 31 & 31 & $+700 \%$ \\
\hline croquis & 159 & 190 & 190 & $+20 \%$ \\
\hline cul de sac & 15 & 17 & 17 & $+10 \%$ \\
\hline dame (dama) & 2316 & $521+2977$ & 2498 & $+10 \%$ \\
\hline dean (deán) & 52 & $5+61$ & 66 & $+30 \%$ \\
\hline debacle & 214 & 273 & 273 & $+30 \%$ \\
\hline debut (debú) & 64 & $1264+77$ & 1341 & $+2000 \%$ \\
\hline déjà vu & $\mathrm{DI}$ & 35 & 35 & DI \\
\hline deshabillé & 2 & 15 & 15 & $+600 \%$ \\
\hline dossier & 213 & 288 & 288 & $+30 \%$ \\
\hline duvet & $\mathrm{DI}$ & 18 & 18 & DI \\
\hline eau de toilette & $\mathrm{DI}$ & 5 & 5 & $\mathrm{Dl}$ \\
\hline élite (elite) & 78 & $900+752$ & 1652 & $+2000 \%$ \\
\hline entente & 64 & 67 & 67 & $+5 \%$ \\
\hline escalade & $\mathrm{DI}$ & 1 & 1 & DI \\
\hline escalope & 6 & 14 & 14 & $+120 \%$ \\
\hline etiquette (etiqueta) & 1016 & $3+1396$ & 1399 & $+40 \%$ \\
\hline femme fatale & $\mathrm{DI}$ & 26 & 26 & $\mathrm{DI}$ \\
\hline flamboyant & DI & 1 & 1 & DI \\
\hline foie gras (fuagrás) & 50 & $72+4$ & 76 & $+50 \%$ \\
\hline fondant & $\mathrm{DI}$ & 22 & 22 & $\mathrm{DI}$ \\
\hline fondue & 8 & 31 & 31 & $+300 \%$ \\
\hline foyer & 31 & 38 & 38 & $+20 \%$ \\
\hline frappé & $\mathrm{DI}$ & 15 & 15 & $\mathrm{DI}$ \\
\hline fricassée (fricasé) & 10 & $1+11$ & 12 & $+20 \%$ \\
\hline gamin (gamín) & 8 & 8 & 8 & $=$ \\
\hline gigolo (gigoló) & 43 & $8+58$ & 64 & $+40 \%$ \\
\hline gourmet & 70 & 109 & 109 & $+70 \%$ \\
\hline Grand Prix & 1 & 4 & 4 & $+300 \%$ \\
\hline
\end{tabular}




\begin{tabular}{|c|c|c|c|c|}
\hline habitué & 33 & 36 & 36 & $+10 \%$ \\
\hline haute couture & DI & 4 & 4 & $\mathrm{DI}$ \\
\hline hors d'œuvre & DI & 0 & 0 & $\mathrm{DI}$ \\
\hline hotel & 7980 & 10075 & 10075 & $+25 \%$ \\
\hline impasse & 191 & 232 & 232 & $+20 \%$ \\
\hline joint & DI & 150 & 150 & DI \\
\hline kepi (quepis) & 31 & $2+31$ & 33 & $+10 \%$ \\
\hline limousine (limusina) & 87 & $48+118$ & 166 & $+90 \%$ \\
\hline madam & 62 & 63 & 63 & $+1 \%$ \\
\hline madame & 634 & 680 & 680 & $+7 \%$ \\
\hline mademoiselle & 62 & 66 & 66 & $+5 \%$ \\
\hline magnolia & 41 & 44 & 44 & $+10 \%$ \\
\hline maillot & 185 & 199 & 199 & $+10 \%$ \\
\hline maître d'hôtel (maître) & 149 & $0+169$ & 169 & $+10 \%$ \\
\hline massacre (masacre) & 776 & $4+942$ & 946 & $+25 \%$ \\
\hline mêlée (melé) & 42 & $6+47$ & 53 & $+30 \%$ \\
\hline ménage à trois (menage a trois) & 10 & $11+9$ & 20 & $+100 \%$ \\
\hline menu (menú) & 1252 & $3+2296$ & 2299 & $+80 \%$ \\
\hline milieu & 3 & 8 & 8 & $+170 \%$ \\
\hline mode (moda) & 5688 & $19+7189$ & 8208 & $+70 \%$ \\
\hline morgue & $\mathrm{DI}$ & 197 & 197 & DI \\
\hline mousse & 52 & 75 & 75 & $+45 \%$ \\
\hline naïve (naïf) & DI & $4+54$ & 59 & $\mathrm{DI}$ \\
\hline nouvelle cuisine & 13 & 19 & 19 & $+40 \%$ \\
\hline nouvelle vague & 31 & 34 & 34 & $+10 \%$ \\
\hline papier-mâché & DI & 1 & 1 & DI \\
\hline parvenu & 16 & 18 & 18 & $+10 \%$ \\
\hline pastiche & 59 & 80 & 80 & $+30 \%$ \\
\hline patchouli (patchulí/pachulí) & 10 & $1+3+17$ & 21 & $+110 \%$ \\
\hline pâté (paté) & DI & $13+95$ & 108 & $\mathrm{DI}$ \\
\hline patois & 15 & 17 & 17 & $+10 \%$ \\
\hline pell-mell (pêle-mêle) & DI & 0 & 0 & DI \\
\hline peloton (pelotón) & 976 & 1184 & 1184 & $+20 \%$ \\
\hline piolet & DI & 89 & 89 & DI \\
\hline potpourri (popurrí) & 27 & $6+37$ & 43 & $+50 \%$ \\
\hline porch & DI & 5 & 5 & $\mathrm{DI}$ \\
\hline premier & 352 & 439 & 439 & $+30 \%$ \\
\hline premiere (première) & 22 & $41+74$ & 115 & $+500 \%$ \\
\hline prêt-à-porter (prêt a porter) & 69 & $74+18$ & 92 & $+30 \%$ \\
\hline quiche & 5 & 7 & 7 & $+40 \%$ \\
\hline ragout (ragú) & 2 & $3+7$ & 10 & $+400 \%$ \\
\hline rappel & 24 & 30 & 30 & $+20 \%$ \\
\hline rendez-vous (rendibú) & 2 & $11+3$ & 14 & $+600 \%$ \\
\hline reprise (reprís) & 12 & 13 & 13 & $+10 \%$ \\
\hline restaurant (restaurante) & DI & $246+3899$ & 4145 & DI \\
\hline role (rol) & 2231 & $23+2908$ & 2931 & $+60 \%$ \\
\hline rouge & 59 & 66 & 66 & $+10 \%$ \\
\hline sommelier & 6 & 11 & 11 & $+90 \%$ \\
\hline soufflé & 7 & 51 & 51 & $+600 \%$ \\
\hline souvenir & 94 & 109 & 109 & $+15 \%$ \\
\hline suite & 454 & 573 & 573 & $+25 \%$ \\
\hline tarot & 53 & 74 & 74 & $+40 \%$ \\
\hline tête-à-tête & 4 & 11 & 11 & $+175 \%$ \\
\hline toilette & 74 & 81 & 81 & $+10 \%$ \\
\hline tour & 304 & 399 & 399 & $+30 \%$ \\
\hline trompe l'œil & 0 & 0 & 0 & $=$ \\
\hline troupe & 93 & 118 & 118 & $+30 \%$ \\
\hline vedette & 149 & 192 & 192 & $+30 \%$ \\
\hline vis-à-vis (vis-à-vis) & 37 & $9+43$ & 52 & $+40 \%$ \\
\hline voilà & 8 & 8 & 8 & $=$ \\
\hline voyeur & 70 & 82 & 82 & $+20 \%$ \\
\hline zigzag & DI & 164 & 164 & DI \\
\hline
\end{tabular}


2. Muestra testigo de los cien primeros galicismos del DRAE

\begin{tabular}{|c|c|c|c|}
\hline lexema & CREA 2003 & CREA 2013 & Evolución \\
\hline abandonar & 5221 & 6372 & $+20 \%$ \\
\hline abigarrar & 1 & 1 & $=$ \\
\hline abracadabrante & 12 & 13 & $+10 \%$ \\
\hline acaparar & 140 & 183 & $+30 \%$ \\
\hline achelense & 3 & 17 & $+475 \%$ \\
\hline aclimatar & 22 & 25 & $+10 \%$ \\
\hline acoquinar & 3 & 5 & $+75 \%$ \\
\hline adobar & 16 & 21 & $+40 \%$ \\
\hline adosar & 11 & 11 & $=$ \\
\hline aeroplano & 130 & 155 & $+15 \%$ \\
\hline aerosol & 70 & 113 & $+60 \%$ \\
\hline agá & 6 & 2 & $-60 \%$ \\
\hline airón & 3 & 3 & $=$ \\
\hline alear & 9 & 10 & $+10 \%$ \\
\hline alemán & 6555 & 7939 & $+15 \%$ \\
\hline alerón & 17 & 81 & $+400 \%$ \\
\hline alevín & 9 & 24 & $+150 \%$ \\
\hline alexia & 2 & 2 & $=$ \\
\hline alijar & 4 & 9 & $+120 \%$ \\
\hline almete & 1 & 1 & $=$ \\
\hline alternativa & 5746 & 7476 & $+30 \%$ \\
\hline alternativo & 692 & 987 & $+40 \%$ \\
\hline altruismo & 131 & 227 & $+70 \%$ \\
\hline alucinógeno & 39 & 45 & $+15 \%$ \\
\hline alzacuello & 9 & 10 & $+10 \%$ \\
\hline amarrar & 170 & 197 & $+15 \%$ \\
\hline ambigú & 25 & 27 & $+10 \%$ \\
\hline amerizaje & 10 & 11 & $+10 \%$ \\
\hline ancestro & 109 & 166 & $+50 \%$ \\
\hline andriana & 1 & 1 & $=$ \\
\hline anécdota & 1621 & 2044 & $+25 \%$ \\
\hline anfíbol & 2 & 10 & $+400 \%$ \\
\hline anglófono & 17 & 19 & $+10 \%$ \\
\hline anís & 557 & 646 & $+15 \%$ \\
\hline anisete & 13 & 14 & $+10 \%$ \\
\hline anorak & 48 & 58 & $+20 \%$ \\
\hline antibiograma & 3 & 10 & $+220 \%$ \\
\hline antisepsia & 10 & 11 & $+10 \%$ \\
\hline antivariólico & 1 & 1 & $=$ \\
\hline aparellaje & 2 & 11 & $+450 \%$ \\
\hline aproches & 5 & 5 & $=$ \\
\hline arandela & 23 & 34 & $+40 \%$ \\
\hline arcabuz & 52 & 53 & $+2 \%$ \\
\hline archa & 1 & 1 & $=$ \\
\hline argayo & 1 & 0 & $-100 \%$ \\
\hline arlequín & 31 & 71 & $+130 \%$ \\
\hline armañac & 3 & 4 & $+30 \%$ \\
\hline arnés & 376 & 77 & $-80 \%$ \\
\hline arpa & 576 & 452 & $-20 \%$ \\
\hline arpar & 1 & 0 & $-100 \%$ \\
\hline arpeo & 8 & 0 & $-100 \%$ \\
\hline arpillera & 89 & 100 & $+10 \%$ \\
\hline arpón & 71 & 87 & $+20 \%$ \\
\hline arranchar & 1 & 0 & $-100 \%$ \\
\hline artillar & 9 & 1 & $-80 \%$ \\
\hline artillería & 4810 & 1093 & $-75 \%$ \\
\hline asamblea & 992 & 4092 & $+300 \%$ \\
\hline asepsia & 161 & 207 & $+20 \%$ \\
\hline áspic & 14 & 14 & $=$ \\
\hline
\end{tabular}




\begin{tabular}{|c|c|c|c|}
\hline astrofísica & 74 & 120 & $+60 \%$ \\
\hline astronáutica & 14 & 24 & $+80 \%$ \\
\hline aterrizaje & 89 & 675 & $+600 \%$ \\
\hline atoar & 4 & 0 & $-100 \%$ \\
\hline atrapar & 114 & 603 & $+450 \%$ \\
\hline auriñaciense & 2 & 10 & $+400 \%$ \\
\hline autobús & 187 & 2659 & $+2300 \%$ \\
\hline autocar & 24 & 364 & $+1500 \%$ \\
\hline autofocus & 5 & 6 & $+20 \%$ \\
\hline auxina & 9 & 9 & $=$ \\
\hline aval & 48 & 887 & $1900 \%$ \\
\hline avalancha & 129 & 805 & $+550 \%$ \\
\hline avampiés & 2 & 0 & $-100 \%$ \\
\hline avantrén & 3 & 0 & $-100 \%$ \\
\hline avariosis & 4 & 0 & $-100 \%$ \\
\hline avatar & 57 & 73 & $+30 \%$ \\
\hline avión & 5923 & 7308 & $+20 \%$ \\
\hline avizor & 47 & 61 & $+25 \%$ \\
\hline axial & 131 & 172 & $+30 \%$ \\
\hline axiología & 37 & 97 & $+180 \%$ \\
\hline ázoe & 2 & 2 & $=$ \\
\hline azur & 17 & 19 & $+10 \%$ \\
\hline babucha & 3 & 3 & $=$ \\
\hline babuino & 11 & 12 & $+10 \%$ \\
\hline baca & 27 & 31 & $+15 \%$ \\
\hline bachiller & 341 & 420 & $+20 \%$ \\
\hline bacinete & 1 & 1 & $=$ \\
\hline bagatela & 33 & 43 & $+30 \%$ \\
\hline bala & 1439 & 1750 & $+20 \%$ \\
\hline balance & 3115 & 3954 & $+25 \%$ \\
\hline balandra & 12 & 12 & $=$ \\
\hline balaustre & 10 & 10 & $=$ \\
\hline balcanización & 29 & 30 & $+5 \%$ \\
\hline balduque & 5 & 5 & $=$ \\
\hline balota & 2 & 2 & $=$ \\
\hline balotada & 1 & 1 & $=$ \\
\hline balotaje & 7 & 8 & $+10 \%$ \\
\hline baluarte & 233 & 290 & $+30 \%$ \\
\hline banal & 383 & 521 & $+30 \%$ \\
\hline
\end{tabular}

